\title{
Custom-made talar component of total ankle replacement implant, with or without lateral articular facet: A finite element analysis
}

\section{Min Zhu}

People's Liberation Army Joint Logistic Support Force 920th Hospital

\section{Kang-lai Tang}

Army Medical University

\section{Zhong-min Jin}

Southwest Jiaotong University

\section{Zhi Xu}

People's Liberation Army Joint Logistic Support Force 920th Hospital

\section{Guo-cheng Feng}

People's Liberation Army Joint Logistic Support Force 920th Hospital

\section{Yong-qing Xu ( $\nabla$ xuyongqingkm@163.net)}

\section{Research article}

Keywords: Ankle joint, prosthesis design, Finite element analysis, 3D printing, Custom-made, 3D models

Posted Date: February 18th, 2020

DOI: https://doi.org/10.21203/rs.2.23817/v1

License: (9) This work is licensed under a Creative Commons Attribution 4.0 International License. Read Full License 


\section{Abstract}

Background: The present patient dissatisfaction with and high failure rates of total ankle replacement (TAR) are likely due to current prosthesis designs, which are not patient-specific and anatomy-based, leading to unphysiological motion at the replaced joint. The design of customized prostheses is already possible by means of medical imaging and additive manufacturing technology.

Methods: In this study, dome and geometric fixtures of custom-made talar components for TAR were designed, and we investigated two kinds of talar components: 2-surface contact type (Type-1, without lateral articular facet) and 3-surface contact type (Type-2, with lateral articular facet). The effects of the above two prostheses on the loading stress of the prosthesis contact surface were comparatively analysed with three-dimensional finite element models.

Results: The maximum and average von Mises stress values of the 3-surface prosthesis were smaller than those of the 2-surface prosthesis. In terms of contact surface pressure, the maximum and average values of the 3-surface prosthesis are almost equal to those of the 2- surface type. In terms of the tangential slip distribution of the contact surface, the maximum and average values of the 3-surface prosthesis were smaller than those of the 2-surface prosthesis.

Conclusions: The custom-made talar component of the total ankle replacement implant reproduced the anatomical morphology of the natural articular surfaces well. The 3-surface contact type prosthesis with lateral articular facet, compared to the 2-surface contact type without lateral articular facet, offers better static stability by affecting the internal and external forces.

\section{Background}

Total ankle replacement (TAR) was first introduced in the 1970s[1]. Despite continuous improvements in the past half century, the survivorship rate of TAR implants still lags behind that of total hip or knee replacements[2, 3]. The design of modern TAR implants, especially that of the talar component, still fails to meet the complex biomechanics and kinematics of ankle joints[4]. The Salto Talaris is a precision fixed-bearing design based on the Salto mobile-bearing ankle prosthesis in Europe, which has been in use since 1997[5-7]. The anatomic design of the talar component reproduces normal ankle kinematics without overstressing the deltoid ligaments. A central peg is also incorporated for stabilization[8]. An independent series showed an estimated 87\% 5-year survivorship, but failures and patient dissatisfaction continue to be reported $[6,9,10]$. Failures are mainly due to a mismatch with the original joint because prosthesis geometries are produced in a limited number of sizes and shapes[11].

Currently, the design of customized prostheses is already possible by means of medical imaging and additive manufacturing (AM) technology, also known as 3D printing (3DP) [11, 12]. The lateral talus was resurfaced in the Salto TAR prosthesis, but the medial facet was not. However, other TAR systems, such as INBONE (Wright Medical Group), Trabecular Metal Total Ankle (Zimmer Biomet), VANTAGE (Exactech) and Cadence (Integra Life-Sciences), commonly used in the United States[8], only need to resurface the 
top of the talus. The purpose of the present study was to investigate the difference in the custom-made talar component of TAR implants with or without lateral articular facets by finite element analysis (FEA).

\section{Materials And Methods}

\section{Establishment of the three-dimensional (3D) model}

\subsection{Establishment of the talar 3D model}

A healthy male volunteer was selected who was 37 years old and had a height of $170 \mathrm{~cm}$ and a body weight of $65 \mathrm{~kg}$; foot tumour, deformation and other lesions were excluded. The left foot and ankle scan was obtained from a cone-beam CT (CBCT) scan using a PedCAT scanner (Curvebeam, USA), and the 3D reconstruction of different parts was completed with Mimics software. Triangular mesh models of the talus were reconstructed using a visualization software package (Mimics 19.0 Materialise, Leuven, Belgium). A triangular meshed model was imported into reverse engineering software (Geomagic studio 10.0, Geomagic, Research Triangle Park, NC), and the triangle mesh surface was translated into the NURBS surface. Then, a solid model of the left talus was obtained, as shown in Fig. 1.

\subsection{Establishment of 3D model of custom-made talar component}

The talar 3D model was imported into Pro/Engineer software. The custom-made talar component for TAR was designed based on the talar 3D model. In reference to the design of the central peg of the talar component of the Salto Talaris total ankle prosthesis, two pins were designed in the posterior body of the prosthesis. The two pins were arranged in an isosceles triangle with the central peg.

\section{Experimental Grouping and FEA}

\subsection{D modelling and designing}

Referring to the osteotomy concept of the TAR prosthesis and whether to perform osteotomy on the lateral articular facet of the talus, two kinds of custom-made talar components were used for the TAR implants: a 2-surface contact type (Type-1), as shown in Fig. 2, and a 3-surface contact type (Type-2), as shown in Fig. 3. At the same time, two kinds of talus models after osteotomy matched the 2-surface prosthesis (Fig. 4A) and the 3-surface prosthesis (Fig. 4B).

\subsection{Model assembly}

Taking Type-1 as an example, the details of the prosthesis and bone installation are shown in Fig. 5 . With 3D CAD software (SolidWorks), the front contact surface and the back contact surface of the talus were assembled with the corresponding parts of the prosthesis, as shown in Fig. 6 . The method used to set a Type-2 assembly was similar.

\subsection{Mesh}


Taking the 3-surface prosthesis and talus as an example, the 2-surface types were similar (Fig. 7 and Fig. 8). The assembled solid model was imported into HyperMesh 14.0, and the mesh cell size was set at the edge of the contact area as the front contact surface (Area A) divided by the mesh unit size of 0.1 ; the main contact area was set as the back contact surface (Area B) divided by the mesh unit size of 0.6 ; the non-contact area was set as the lateral contact surface (Area $C$ ) divided by the mesh unit size of 1.0. The mesh information of the two modelling groups is shown in Table 1 and Table 2. The mesh assembly of the models was obtained as shown in Fig. 9.

\subsection{Material properties and Interactions}

HyperMesh 14.0 was used to import the mesh model into the finite element software Abaqus 6.13(Hibbitt, Karlsson \& Sorenson, Inc., Providence, RI, USA); the properties were set to be isotropic, and Young's modulus and Poisson's ratio are shown in Table 3. Each contact surface was set as normal hard contact with no friction and tangential contact with friction. To ensure the static balance of loads, the friction coefficient of this model was set to 0.5 . According to the requirements of the surgical installation, the main fixed connection parts (cylinder and pins) were set as TIE constraints. Then, there were two pairs of contacts and three TIE pairs for a 2-surface model and three pairs of contacts and three TIE pairs for a 3surface model.

\subsection{Boundary conditions and load}

Fixing the lower surface of the talus means locking 3 translational degrees of freedom and 3 rotational degrees of freedom. According to the extended position of the contact force of the talus and tibia, this position is set as the application position of the contact resultant force point (Fig. 10), i.e., the reference point (RP). Then, the coupling method is used to constrain the reference point RP to the upper surface of the CoCrMo prosthesis. The contact force of the ankle joint in the main direction (axial), anterior-posterior direction, and medial-lateral direction under a complete gait was shown[13]. The typical load time point, i.e., contact forces of 0.48 and 0.5 , were selected on the transverse axis as the load (Fig. 11). Based on a body weight of $65 \mathrm{~kg}$, the corresponding Newtonian force is obtained. Typical contact forces in the three directions are shown in Table 4 (Unit: BW, bodyweight) and Table 5 (Unit: $\mathrm{N}$ ). The material of the prosthesis is calculated with an elastic modulus of $220 \mathrm{GPa}$ under two types and two loads.

\section{Results}

\section{Von Mises stress}

The maximum and the average von Mises stress of the prosthesis contact surface were calculated and are shown in Table 6 and Figs. 12-13. Under Load 1 or Load 2, the maximum and average values of von Mises stress of Type- 2 were lower than those of Type- 1 .

\section{Contact surface pressure (CPRESS)}


The maximum and average CPRESS of the prosthesis contact surface were calculated and are shown in Tables 7-9 and Figs. 14-16. Under Load 1, both the maximum and average values of the CPRESS of Type 2 were slightly higher than those of Type 1 . Under load 2, the maximum CPRESS of Type-2 was slightly higher than that of Type-1, and the average CPRESS of Type-2 was lower than that of Type-1. In detail, under Load 1, the maximum CPRESS of P1 of Type-2 was slightly higher than that of Type-1, and the average value was lower than that of Type-1. The maximum and average values of the CPRESS on the P2 surface of Type-2 were slightly higher than those of Type-1. Under Load 2, the maximum CPRESS of the P1 surface of Type- 2 was slightly higher than that of Type-1, and the average value was lower than that of Type-1. The maximum and average values of the CPRESS on the P2 surface of Type-2 were higher than those of Type-1.

\section{Tangential slip distribution of the contact surface (CSLIP)}

The CSLIPs of Type-1 and Type-2 under Load 1 and Load 2 were calculated and are shown in Tables 1012 and Figs. 17-19. Under Load 1 or Load 2, the tangential slip components (CSLIP1 and CSLIP2) of the contact surface were calculated by the model, which were combined according to the formula to obtain the CSLIP. To obtain the overall CSLIP cloud map, Python language is used to merge the data of P1, P2, and P3 into an ODB file.

$$
\text { CSLIP }=\sqrt{\text { CSLIP1 }^{2}+\text { CSLIP2 }^{2}}
$$

In general, under Loads 1 and 2, both the maximum and average values of CSLIP of the contact surface of the 3-surface prosthesis were greater than that of Type-1. In detail, under Load 1, the maximum and average values of CSLIP on the P1 and P2 surfaces of Type-2 were smaller than those of Type- 1 . The results show that the CSLIP of contact surfaces P1 and P2 decreased when there was a medial-lateral load, which proves that the P3 surface supports the lateral force. Under Load 2, the maximum and average values of CSLIP on the P1 surface of Type-2 were smaller than those of Type-1. The maximum and average values of CSLIP on the contact surface of P2 were larger than those of the two sides. The CSLIP of the P3 contact surface was larger than that of the other surfaces.

\section{Mesh sensitivity analysis}

The model used in this report has been tested for mesh sensitivity; thus, the results are true and effective.

\section{Discussion}

The kinematic properties of the ankle are the result of the geometric features of the articulating surfaces of the trochlea and the tibial mortise[14]. Researchers have shown that currently available TAR implants, especially the designs of talar components, fail to restore physiologic ankle mobility[15-17]. Selective laser melting (SLM) is a new additive manufacturing (AM) technology that can be used for fabricating complex metallic products[18]. AM or 3DP can enable careful personalization of prosthesis design for human joints according to the specific morphology of each ankle joint[12]. 
Lateral articular facets were designed in the talar component of the Salto TAR prosthesis, and lateral and medial articular facets were designed in Scandinavian Total Ankle Replacement (STAR)[19]. None of the lateral or medial articular facets were designed in the INBONE system, VANTAGE or Cadence [8, 20-22] prostheses. The results herein indicate show that the increased contact surface of the 3-surface prosthesis mainly affects the internal and external forces. Under Load 1, there was a large load component in the medial-lateral direction. Both the maximum and the average values of the Von Mises stress of the 3-surface prosthesis were smaller than those of the 2-surface prosthesis. The average CPRSS of P1 was smaller than that of the 2-surface type, and the average CPRSS of P2 was greater than that of the 2-surface type. The CSLIP of the 3-surface prosthesis on the P1 and P2 surfaces was smaller than that of the 2-surface prosthesis. Similarly, under Load 2, there was no load in the medial-lateral direction. The maximum and average values of von Mises stress of the 3-surface prosthesis were smaller than those of the 2-surface prosthesis.

Therefore, based on the obtained results, it can be observed that the 3-surface prosthesis has better static stability than the 2-surface prosthesis. At the same time, the CSLIP of the lateral articular facet was larger than that of other surfaces, especially at the farthest point part. On the other hand, the increased osteotomy will affect the talar blood supply and damage the ligaments around the talus, increasing surgical difficulty. When the prosthesis is designed, short and wide lateral articular facets may improve the stability of the prosthesis and avoid stress concentration.

\section{Conclusions}

The custom-made talar component of the total ankle replacement implant reproduced the anatomical morphology of the natural articular surfaces well. The results obtained in this study suggest that the 3surface contact type prosthesis with lateral articular facet, compared to the 2-surface contact type without lateral articular facet, has better static stability by affecting the internal and external forces. Whether this will improve the survivorship rate of TAR implants is still subject to future biological and clinical research.

\section{Abbreviations}

TAR, total ankle replacement; AM, additive manufacturing; 3D, three-dimensional; 3DP, 3D-Printing; FEA, finite element analysis; $C B C T$, cone-beam CT; CPRESS, contact surface pressure; CSLIP, tangential slip distribution of contact surface; SLM, selective laser melting.

\section{Declarations}

\section{Ethics approval and consent to participate}

The study was approved by the Clinical Academic Committee of People's Liberation Army Joint Logistic Support Force 920th Hospital and was approved by all the members. The study was conducted in 
compliance with the Helsinki Declaration.

\section{Consent for publication}

All volunteers enrolled into the study agree the use of patients' data for research.

\section{Availability of supporting data}

All data and materials were in full compliance with the journal's policy.

\section{Competing interests}

All authors declare that they have no conflicts of interest.

\section{Funding}

This study was supported by Clinical Medical Center of Yunnan (No. ZX20191001) and the National Key Research and Development Plan (No. 2016YFC1100500).

\section{Authors'contributions}

Three-dimensional finite element analysis were carried out by M Z, K-L T and Z-M J, Z X and G-T F carried out manuscript writing. All authors have read and approved the final manuscript.

\section{Acknowledgments}

We acknowledge the assistance of investigators and all subjects for participants in this study.

\section{Authors' information}

M-Z, Z X, G-C F and Y-Q X come from Department of Orthopaedics, People's Liberation Army Joint Logistic Support Force 920th Hospital, 212 Da guan Road, Xishan District, Kunming City, Yunnan, 650032, People's Republic of China.

K-L T comes from Sports Medicine Center, Southwest Hospital, The Army Military Medical University, Gaotanyan Str. 30, Chongqing city, 400038, People's Republic of China.

Z-M J comes from school of Mechanical Engineering, Southwest Jiaotong University, 610031 Chengdu, Sichuan, China.

\section{References}

1. Lord G, Marotte JH: Total ankle prosthesis. Technic and 1st results. Apropos of 12 cases. Rev Chir Orthop Reparatrice Appar Mot 1973, 59(2):139-151.

2. Labek G, Thaler M, Janda W, Agreiter M, Stockl B: Revision rates after total joint replacement: cumulative results from worldwide joint register datasets. The Journal of bone and joint surgery British volume 2011, 93(3):293-297. 
3. Gougoulias N, Maffulli N: History of total ankle replacement. Clinics in podiatric medicine and surgery 2013, 30(1):1-20.

4. Siegler S, Toy J, Seale D, Pedowitz D: The Clinical Biomechanics Award 2013 -- presented by the International Society of Biomechanics: new observations on the morphology of the talar dome and its relationship to ankle kinematics. Clinical biomechanics 2014, 29(1):1-6.

5. Morris $\mathrm{CH}$, Christensen JC, Ching RP, Chan F, Schuberth JM: Articular congruency of the Salto Talaris total ankle prosthesis. Foot and ankle surgery : official journal of the European Society of Foot and Ankle Surgeons 2015, 21(3):206-210.

6. Schweitzer KM, Adams SB, Viens NA, Queen RM, Easley ME, Deorio JK, Nunley JA: Early prospective clinical results of a modern fixed-bearing total ankle arthroplasty. The Journal of bone and joint surgery American volume 2013, 95(11):1002-1011.

7. Besse JL, Colombier JA, Asencio J, Bonnin M, Gaudot F, Jarde O, Judet T, Maestro M, Lemrijse T, Leonardi $\mathrm{C}$ et al: Total ankle arthroplasty in France. Orthopaedics \& traumatology, surgery \& research : OTSR 2010, 96(3):291-303.

8. Gross CE, Palanca AA, DeOrio JK: Design Rationale for Total Ankle Arthroplasty Systems: An Update. J Am Acad Orthop Surg 2018, 26(10):353-359.

9. Gaudot F, Colombier JA, Bonnin M, Judet T: A controlled, comparative study of a fixed-bearing versus mobile-bearing ankle arthroplasty. Foot \& ankle international 2014, 35(2):131-140.

10. K S, S L, M J, K F, S M, E L, W N: Prospective study of a cementless, mobile-bearing, third generation total ankle prosthesis. Foot \& ankle international 2011, 32(8):755-763.

11. Liverani E, Fortunato A, Leardini A, Belvedere C, Siegler S, Ceschini L, Ascari A: Fabrication of Co-CrMo endoprosthetic ankle devices by means of Selective Laser Melting (SLM). Materials \& Design 2016, 106:60-68.

12. C B, S S, A F, P C, E L, S D, A E, T K, A L: New comprehensive procedure for custom-made total ankle replacements: Medical imaging, joint modeling, prosthesis design, and 3D printing. Journal of orthopaedic research : official publication of the Orthopaedic Research Society 2018, undefined(undefined): undefined.

13. Gundapaneni D, Tsatalis JT, Laughlin RT, Goswami T: Wear characteristics of WSU total ankle replacement devices under shear and torsion loads. Journal of the mechanical behavior of biomedical materials 2015, 44:202-223.

14. Siegler S, Toy J, Seale D, Pedowitz D: New observations on the morphology of the talar dome and its relationship to ankle kinematics. Clin Biomech 2013, 29:1-6.

15. Baxter JR, Sturnick DR, Demetracopoulos CA, Ellis SJ, Deland JT: Cadaveric gait simulation reproduces foot and ankle kinematics from population-specific inputs. J Orthop Res 2016, 34(9):1663-1668.

16. Pappas MJ, Buechel FF, Sr.: Failure modes of current total ankle replacement systems. Clinics in podiatric medicine and surgery 2013,30(2):123-143. 
17. Angthong $C$, Chumchuen S, Khadsongkram A: A systematic review of intermediate-term outcomes and failure rates for total ankle replacements: an Asian perspective. Foot and ankle surgery : official journal of the European Society of Foot and Ankle Surgeons 2013, 19(3):148-154.

18. Zhang MK, Yang YQ, Song CH, Bai YC, Xiao ZF: An investigation into the aging behavior of CoCrMo alloys fabricated by selective laser melting. Journal of Alloys and Compounds 2018, 750:878-886.

19. Seth A: A review of the STAR prosthetic system and the biomechanical considerations in total ankle replacements. Foot and ankle surgery : official journal of the European Society of Foot and Ankle Surgeons 2011, 17(2):64-67.

20. Hsu AR, Haddad SL: Early clinical and radiographic outcomes of intramedullary-fixation total ankle arthroplasty. The Journal of bone and joint surgery American volume 2015, 97(3):194-200.

21. Scott RT, Witt BL, Hyer CF: Design comparison of the INBONE I versus INBONE II total ankle system. Foot \& ankle specialist 2013, 6(2):137-140.

22. Barg A, Bettin CC, Burstein AH, Saltzman CL, Gililland J: Early Clinical and Radiographic Outcomes of Trabecular Metal Total Ankle Replacement Using a Transfibular Approach. The Journal of bone and joint surgery American volume 2018, 100(6):505-515.

\section{Tables}

Table 1. Mesh parameters of 2-surface prosthesis and talus

\begin{tabular}{|c|c|c|c|c|c|}
\hline Part & Mesh mode & Element Type & Element size & Total number of elements & Total number of nodes \\
\hline Talus & Global & C3D4 & $0.1 / 0.6 / 1.0$ & 196876 & 42137 \\
\hline Prosthesis & Global & C3D4 & $0.1 / 0.6 / 1.0$ & 107397 & 24830 \\
\hline
\end{tabular}

Table 2. Mesh parameters of 3-surface prosthesis and talus

\begin{tabular}{llllll}
\hline Part & Mesh mode & Element Type & Element size & Total number of elements & Total number of nodes \\
\hline Talus & Global & C3D4 & $0.1 / 0.6 / 1.0$ & 223492 & 48002 \\
Prosthesis & Global & C3D4 & $0.1 / 0.6 / 1.0$ & 148714 & 33409 \\
\hline
\end{tabular}

Table 3. Material properties

\begin{tabular}{ccc}
\hline Material & Young's modulus & Poisson's ratio \\
\hline Bone & 8370MPa & 0.3 \\
CoCrMo & $\begin{array}{c}\text { 1. Entity, 220GPa. } \\
\text { 2.Porosity. 60\%. 26.6GPa }\end{array}$ & 0.3 \\
\hline
\end{tabular}


Table 4. Typical contact forces in the three directions (bodyweight, BW)

\begin{tabular}{lllll}
\hline & time & M-Lload(X) & A-P load(Y) & Axial Load(Z) \\
\hline Load 1 & 0.48 & -0.8 & 0.8 & -5 \\
Load 2 & 0.5 & 0 & 2.2 & -5.2 \\
\hline
\end{tabular}

Table 5. Contact forces in the three directions (Newton, N)

\begin{tabular}{lllll}
\hline & time & M-Lload(X) & A-Pload(Y) & Axial Load(Z) \\
\hline Load 1 & 0.48 & -509.6 & 509.6 & -3185 \\
Load 2 & 0.5 & 0 & 1401.4 & -3312.4 \\
\hline
\end{tabular}

Table 6. Von Mises stress of prosthesis under Load 1 and Load 2 (MPa)

\begin{tabular}{lllll}
\hline & Load 1 & \multicolumn{3}{l}{ Load 2 } \\
\cline { 2 - 5 } & Maximum von Mises stress & Average von Mises stress & $\begin{array}{l}\text { Maximum von } \\
\text { Mises stress }\end{array}$ & $\begin{array}{l}\text { Average von } \\
\text { Mises stress }\end{array}$ \\
\hline .ype-1 & 120.48 & 15.80 & 166.81 & 23.95 \\
.ype-2 & 68.11 & 10.00 & 117.92 & 18.71 \\
\hline
\end{tabular}

Table 7. CPRESS of the prosthesis under Load 1 and Load 2 (MPa)

\begin{tabular}{lllll}
\hline & Load 1 & \multicolumn{3}{c}{ Load 2 } \\
\cline { 2 - 5 } & Maximum & Average & Maximum & Average \\
\hline Type-1 & 42.81 & 3.61 & 66.43 & 4.22 \\
Type-2 & 47.63 & 3.69 & 78.17 & 3.81 \\
\hline
\end{tabular}

Table 8. CPRESS of each contact surface under Load 1 (MPa)

\begin{tabular}{lllllll}
\hline & P1 & \multicolumn{3}{c}{ P2 } \\
\cline { 2 - 7 } & Maximum & Average & Maximum & Average & Maximum & Average \\
\hline Type-1 & 42.81 & 5.15 & 29.40 & 2.30 & - & - \\
Type-2 & 47.63 & 4.32 & 35.99 & 2.78 & 36.33 & 4.21 \\
\hline
\end{tabular}


Table 9. CPRESS of each contact surface under Load 2 (MPa)

\begin{tabular}{lllllll}
\hline & P1 & \multicolumn{5}{c}{ P2 } \\
\cline { 2 - 7 } & Maximum & Average & Maximum & Average & Maximum & Average \\
\hline Type-1 & 66.43 & 8.34 & 3.55 & 0.68 & - & - \\
\hline Type-2 & 78.17 & 8.05 & 6.46 & 1.20 & 21.17 & 2.66 \\
\hline
\end{tabular}

Table 10. CSLIP under Load 1 and Load 2 (mm)

\begin{tabular}{lllll}
\hline & Load 1 & \multicolumn{3}{l}{ Load 2 } \\
\cline { 2 - 5 } & Maximum & Average & Maximum & Average \\
\hline Type-1 & 1.89E-03 & $6.66 \mathrm{E}-04$ & $2.84 \mathrm{E}-03$ & $8.09 \mathrm{E}-04$ \\
Type-2 & $4.99 \mathrm{E}-03$ & $9.62 \mathrm{E}-04$ & $8.44 \mathrm{E}-03$ & $1.70 \mathrm{E}-03$ \\
\hline
\end{tabular}

Table 11. CSLIP of each contact surface under Load 1(mm)

\begin{tabular}{lllllll}
\hline & P1 & \multicolumn{5}{c}{ P2 } \\
\cline { 2 - 7 } & Maximum & Average & Maximum & Average & Maximum & Average \\
\hline Type-1 & $8.68 \mathrm{E}-04$ & $3.79 \mathrm{E}-04$ & $1.89 \mathrm{E}-03$ & $9.20 \mathrm{E}-04$ & - & - \\
Type-2 & $4.48 \mathrm{E}-04$ & $2.13 \mathrm{E}-04$ & $1.21 \mathrm{E}-03$ & $7.23 \mathrm{E}-04$ & $4.99 \mathrm{E}-03$ & $2.08 \mathrm{E}-03$ \\
\hline
\end{tabular}

Table 12. CSLIP of each contact surface under Load 2

\begin{tabular}{lllllll}
\hline & P1 & \multicolumn{3}{c}{ P2 } & P3 \\
\cline { 2 - 7 } & Maximum & Average & Maximum & Average & Maximum & Average \\
\hline Type-1 & $9.13 \mathrm{E}-04$ & $3.54 \mathrm{E}-04$ & $2.84 \mathrm{E}-03$ & $1.21 \mathrm{E}-03$ & - & - \\
Type-2 & $6.67 \mathrm{E}-04$ & $3.31 \mathrm{E}-04$ & $3.23 \mathrm{E}-03$ & $1.26 \mathrm{E}-03$ & $8.44 \mathrm{E}-03$ & 3.72E-03 \\
\hline
\end{tabular}

\section{Figures}




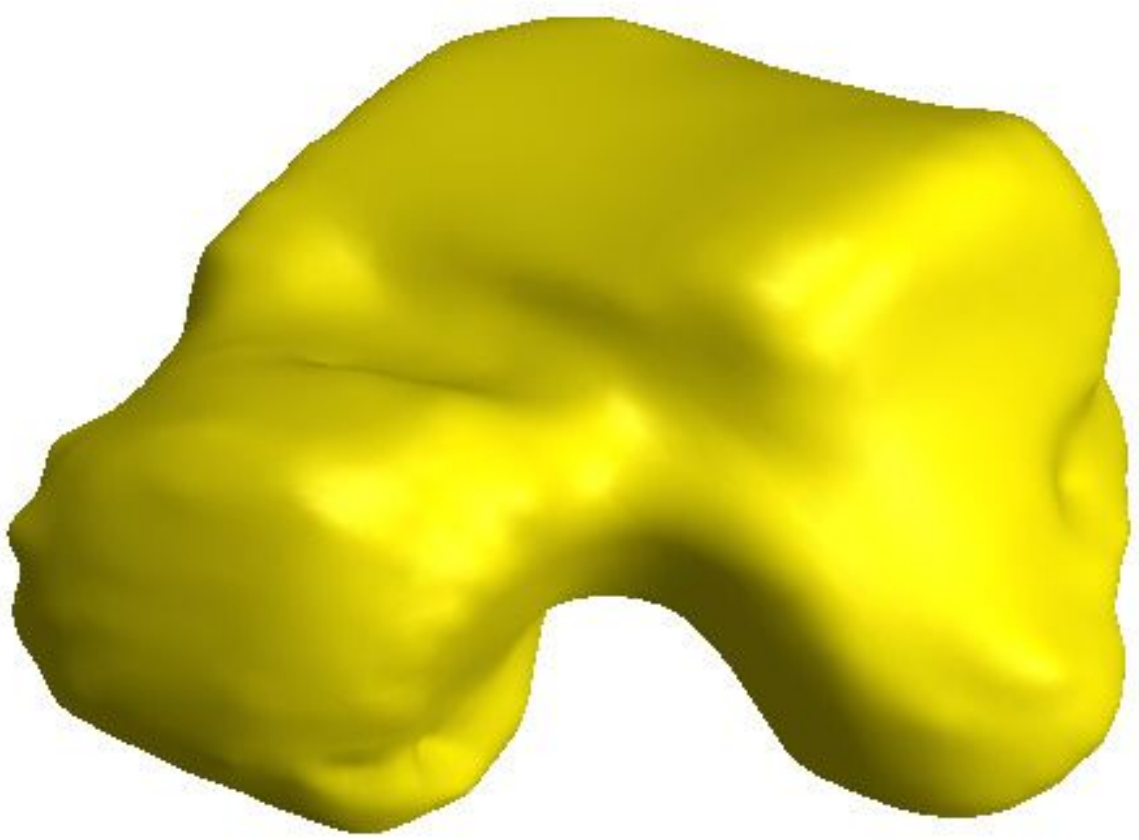

\section{Figure 1}

Solid model of the complete left talus

A

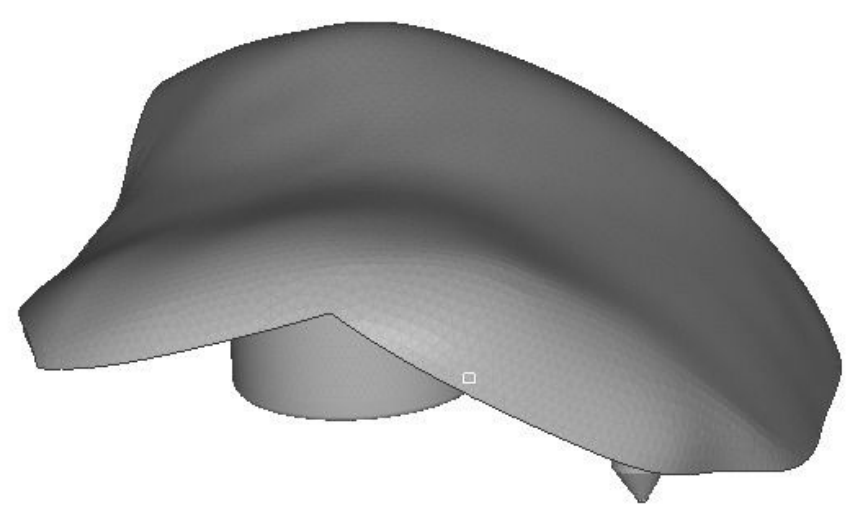

B

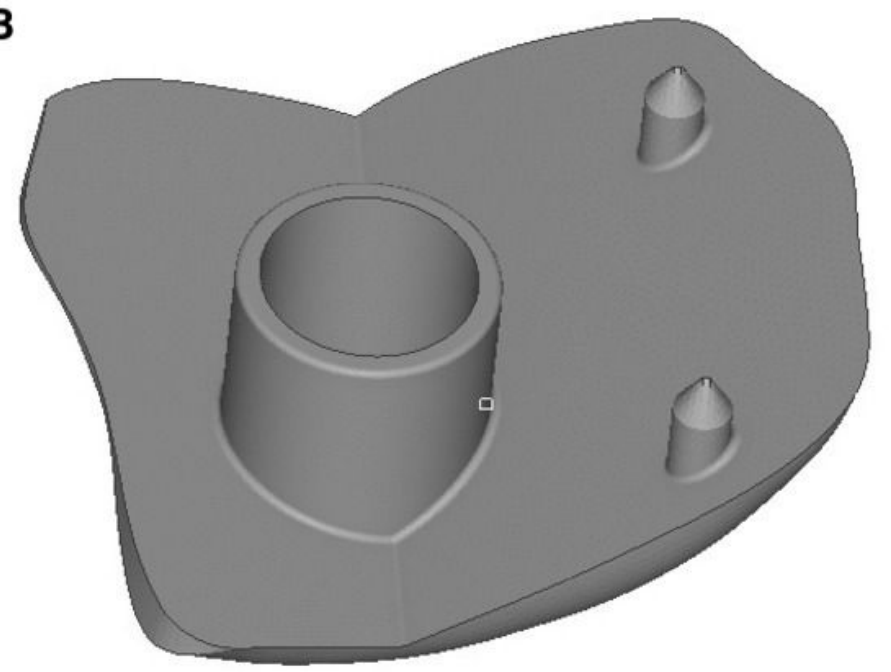

Figure 2

2-surface custom-made talar component(Type-1) 
A

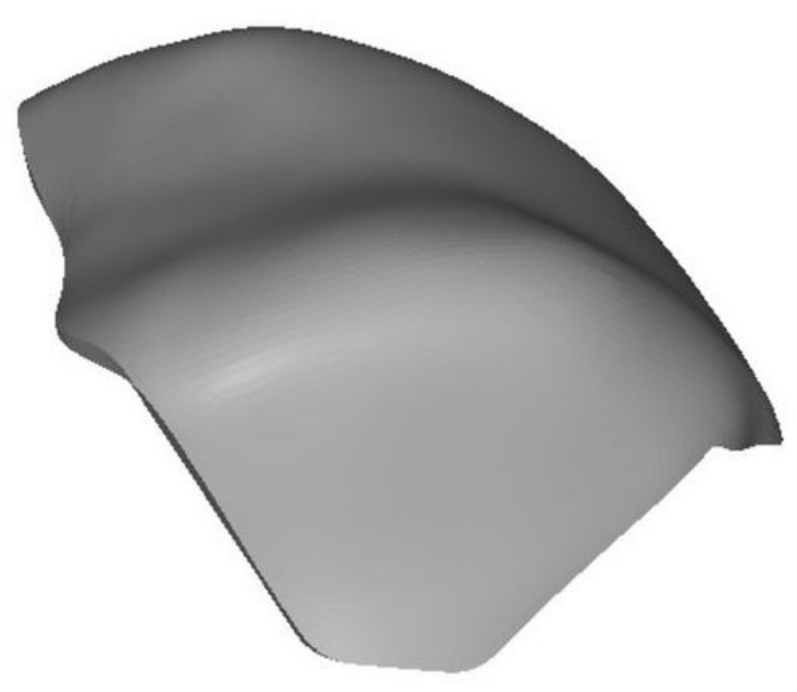

\section{Figure 3}

3-surface custom-made talar component(Type-2)
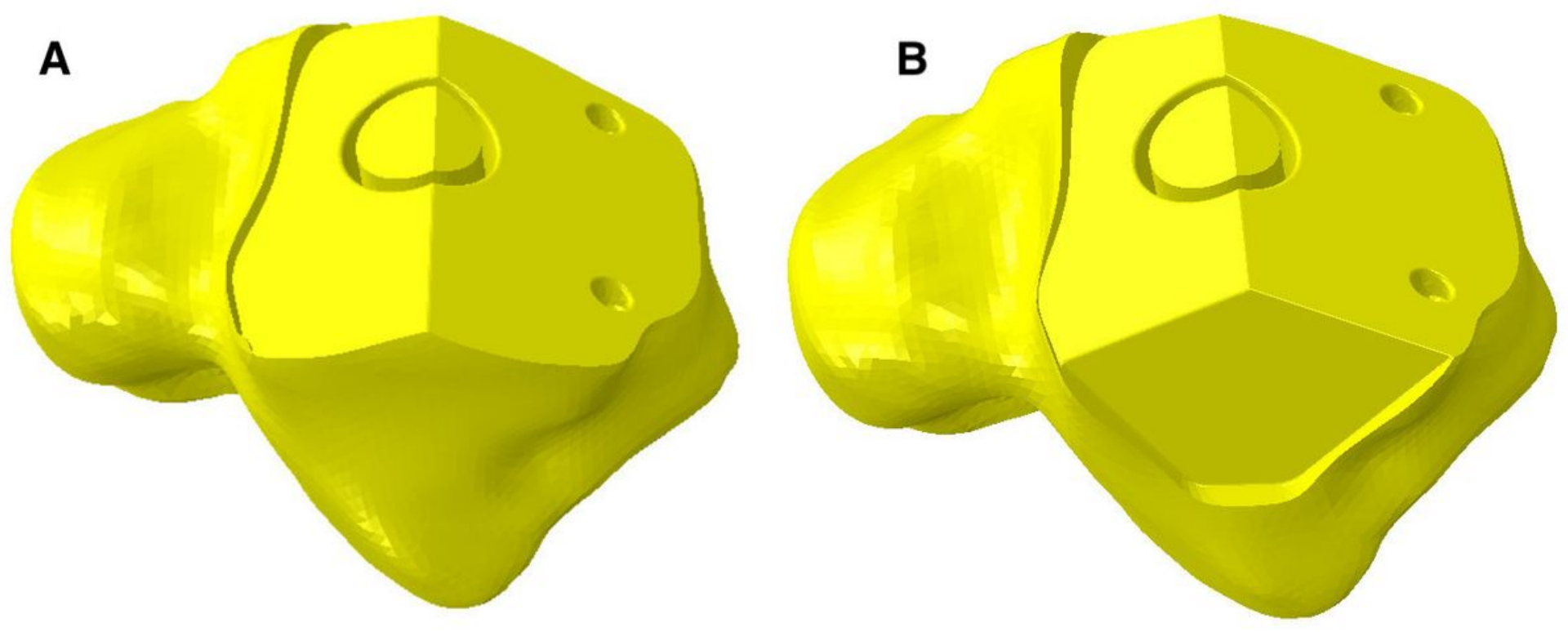

\section{Figure 4}

Talus model after osteotomy matching with the prosthesis(A. Type-1; B. Type-2) 


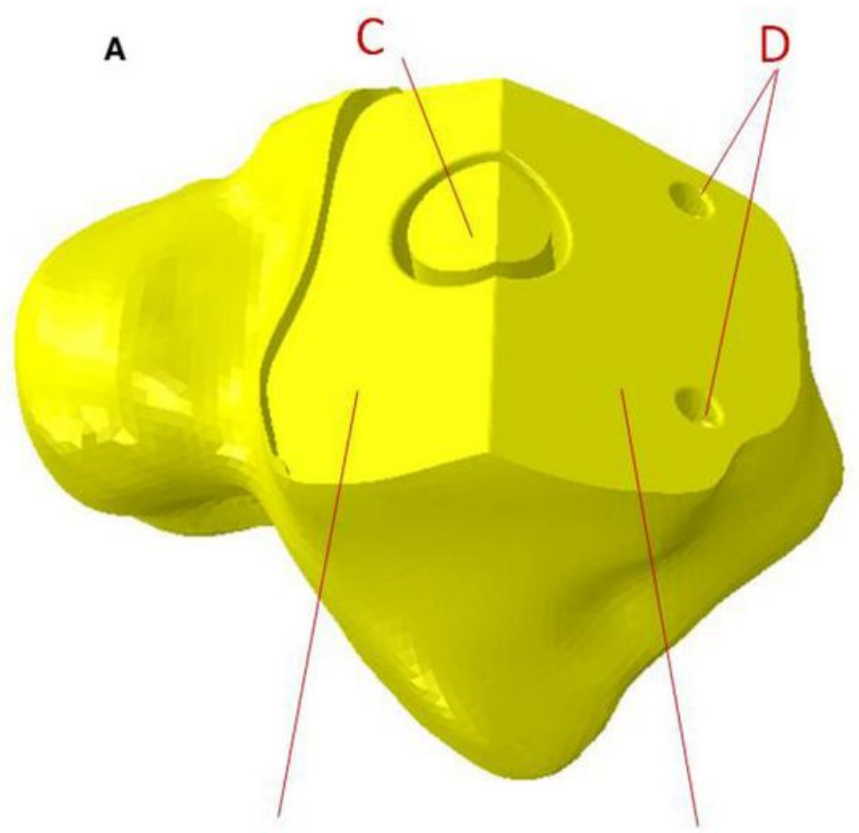

A

B

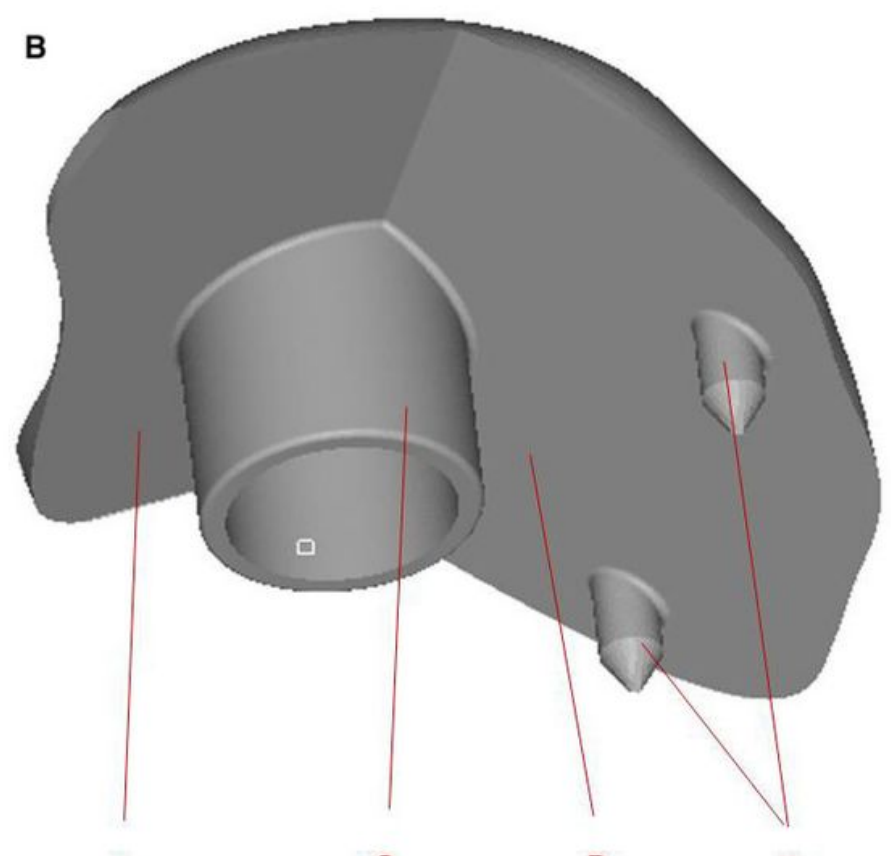

A

C

B

D

\section{Figure 5}

The contact surfaces of the talus and prosthesis. (A. front contact surface; B. back contact surface; C. main fixed connection part; D. back fixed connection part) 


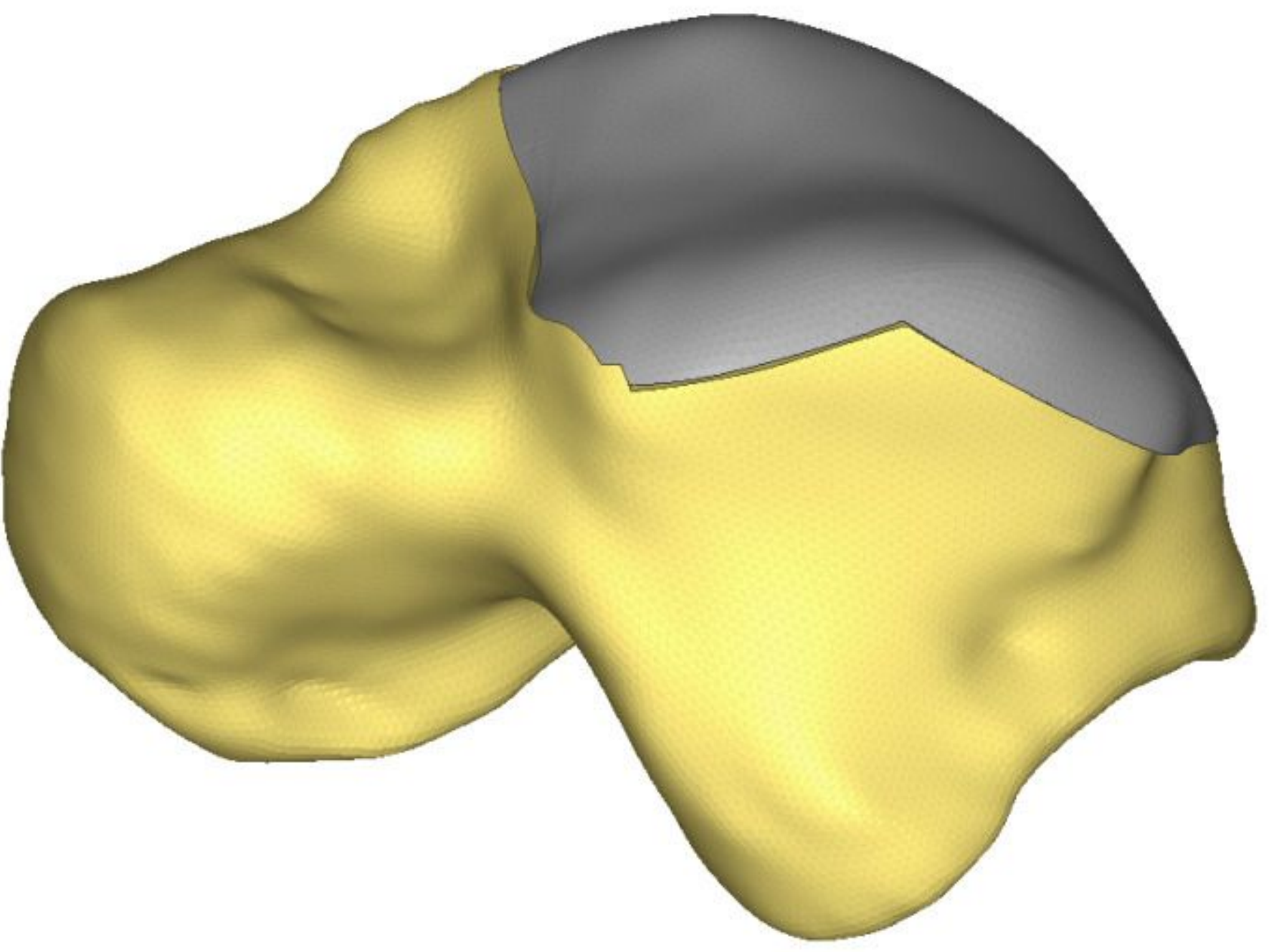

Figure 6

Assembly of prosthesis and talus 

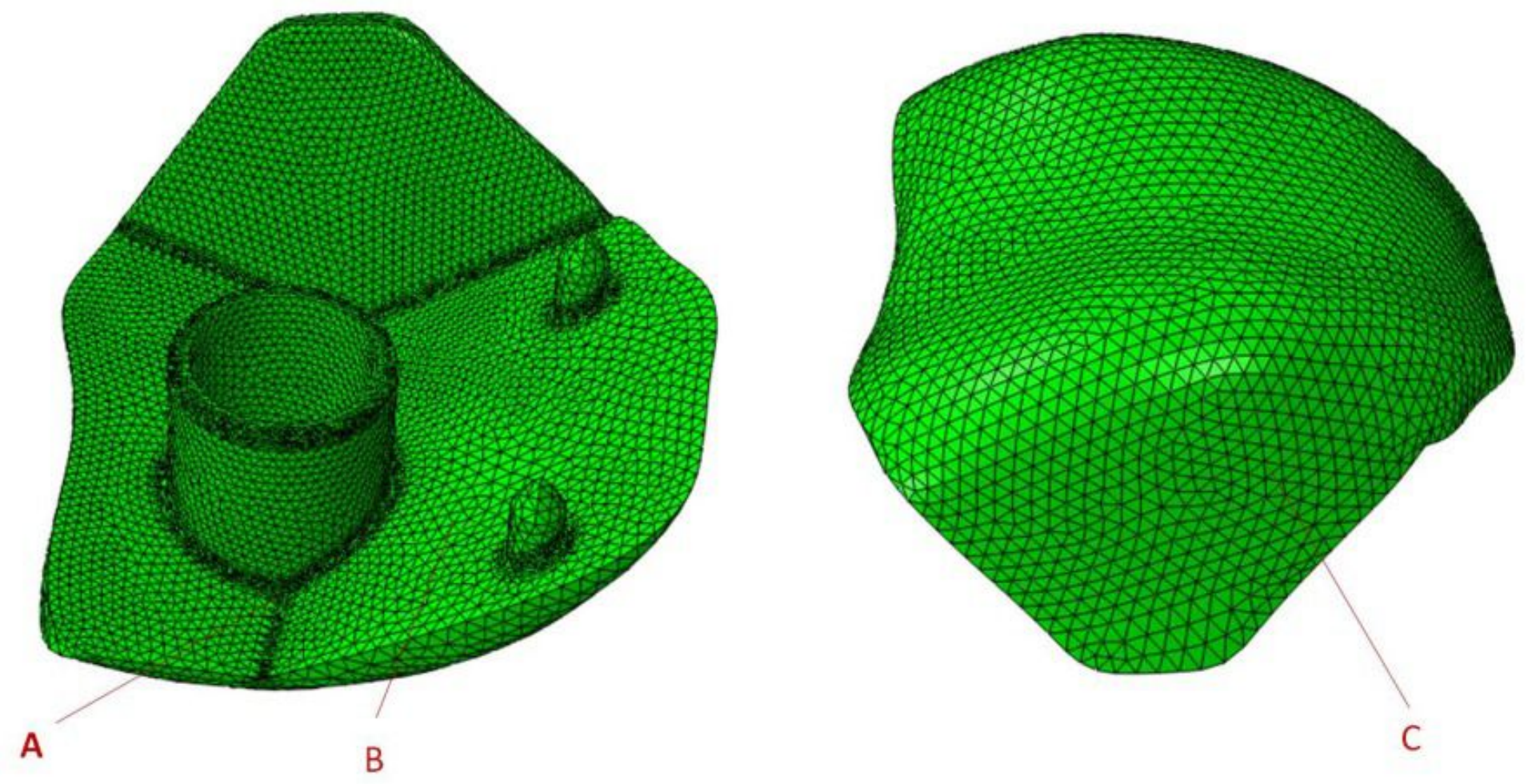

Figure 7

Mesh density partition of prosthesis
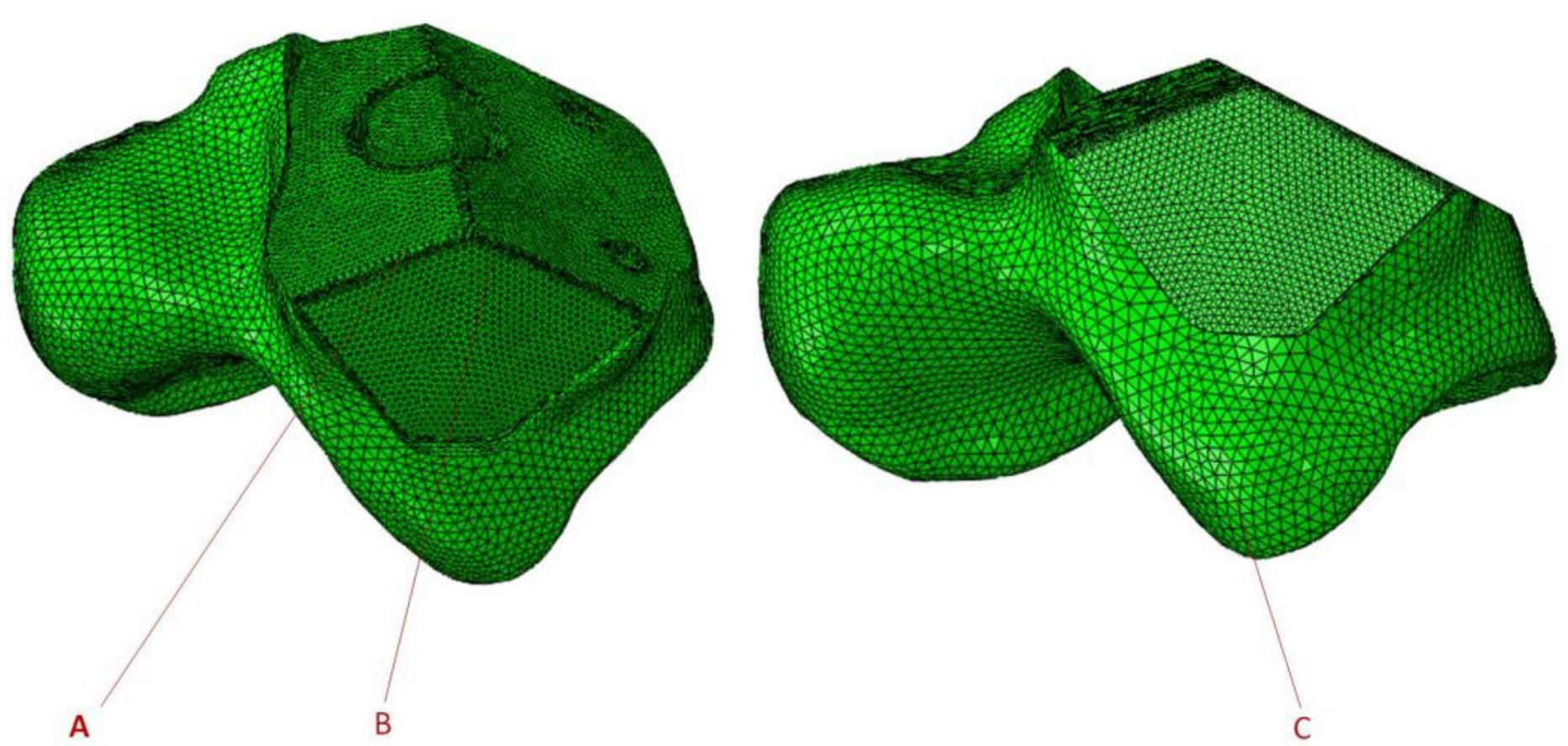

Figure 8

Mesh density partition of the talus 


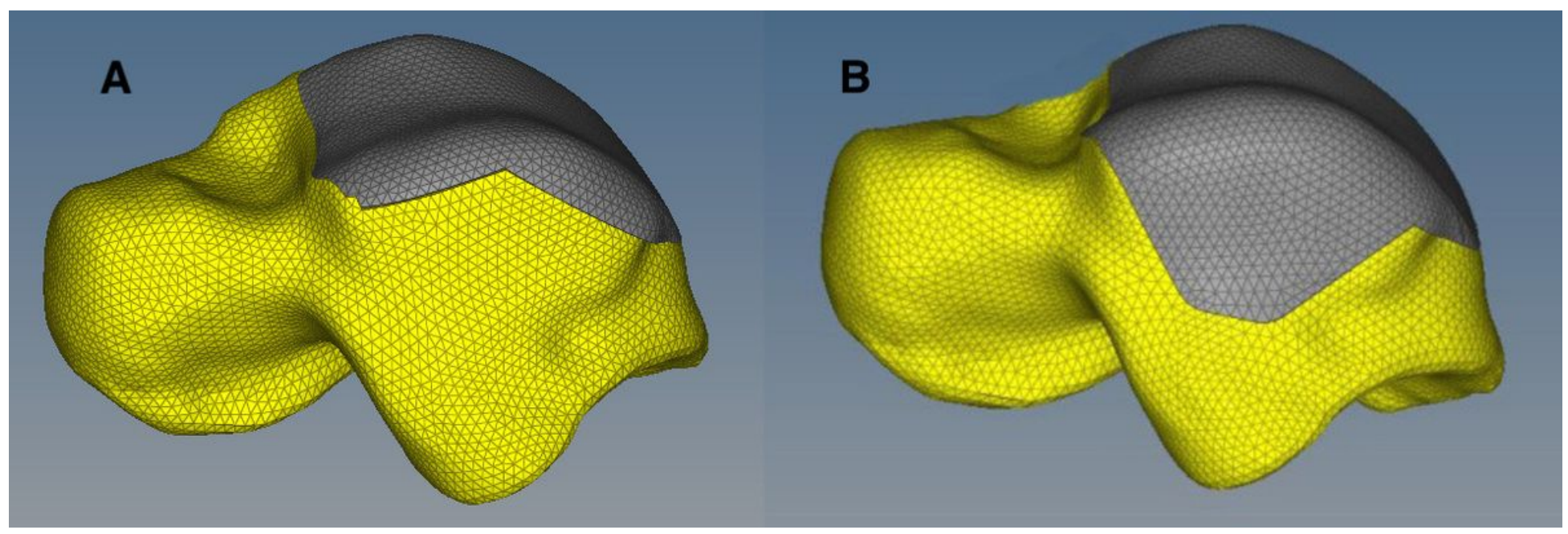

Figure 9

Meshed assembly of the models(A. Type-1; B. Type-2)
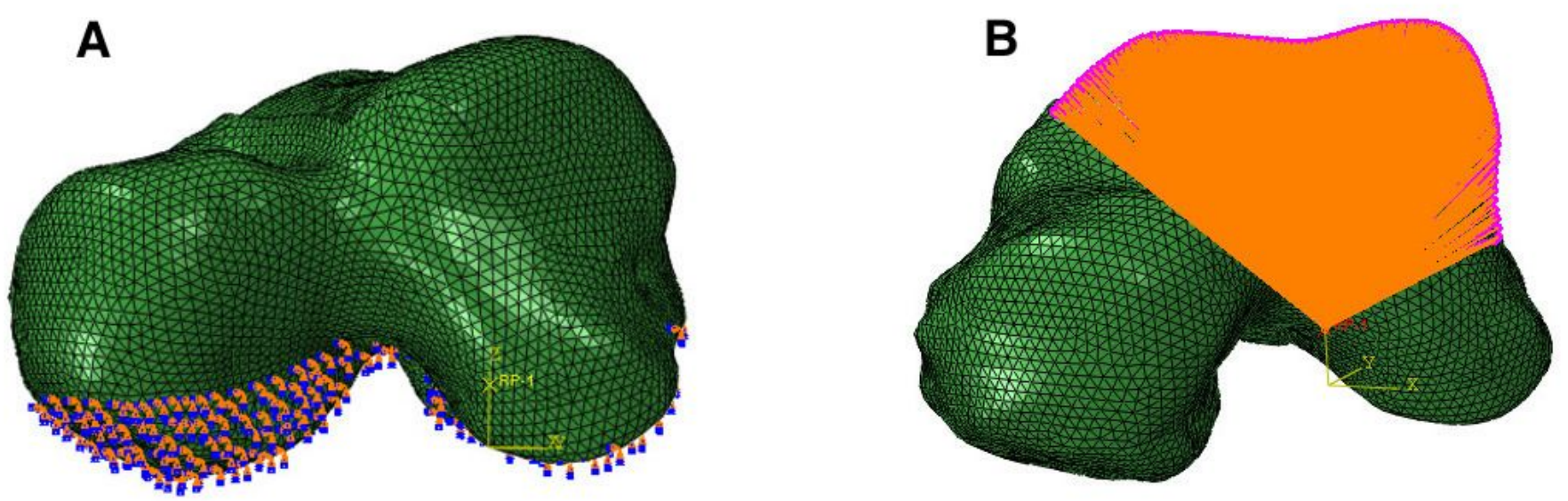

Figure 10

Boundary conditions $(A)$ and load point set(B) 


\section{Forces acting on the Ankle joint}

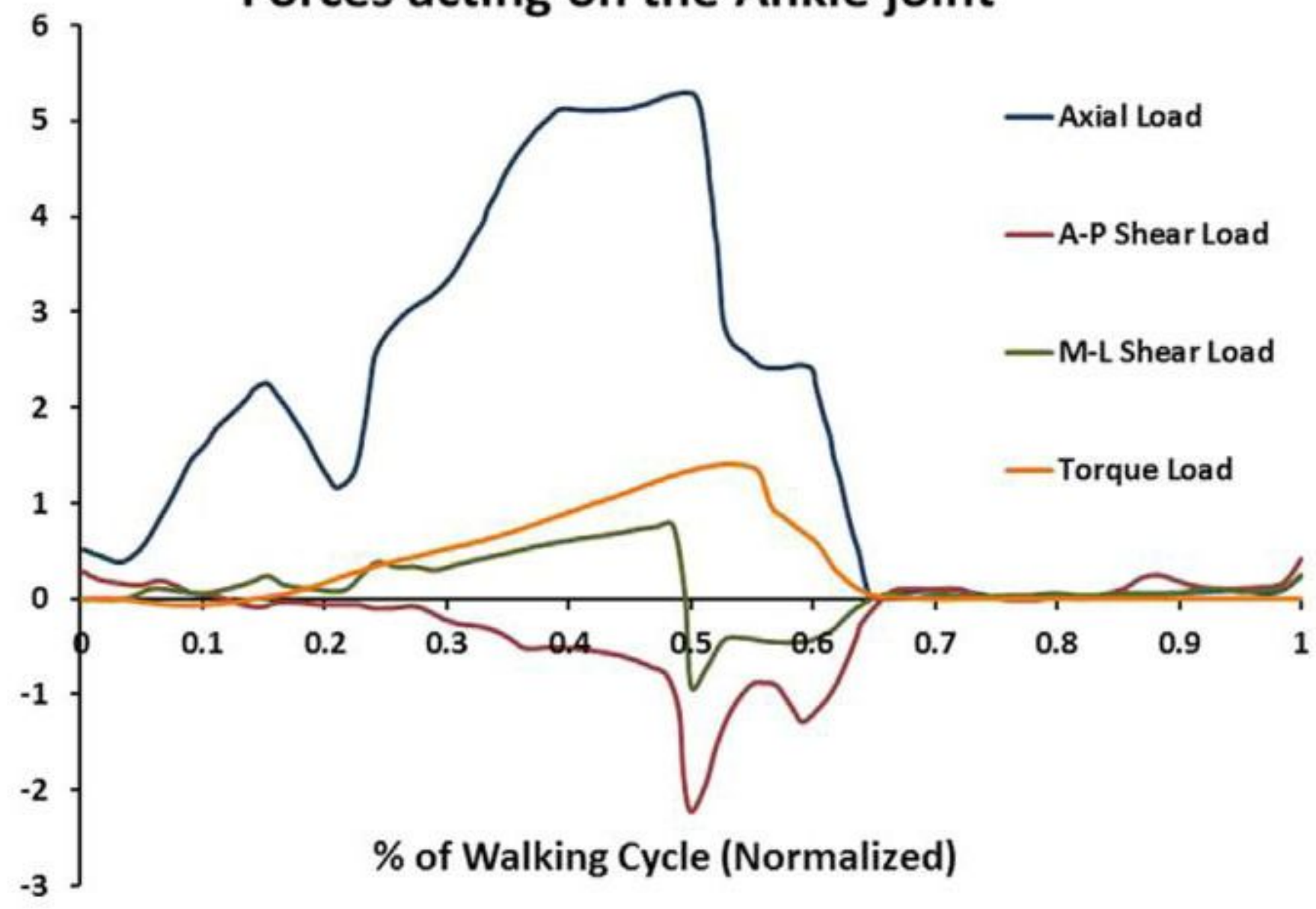

Figure 11

Different force components acting on ankle joint during gait

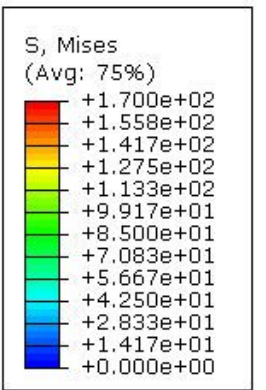

A
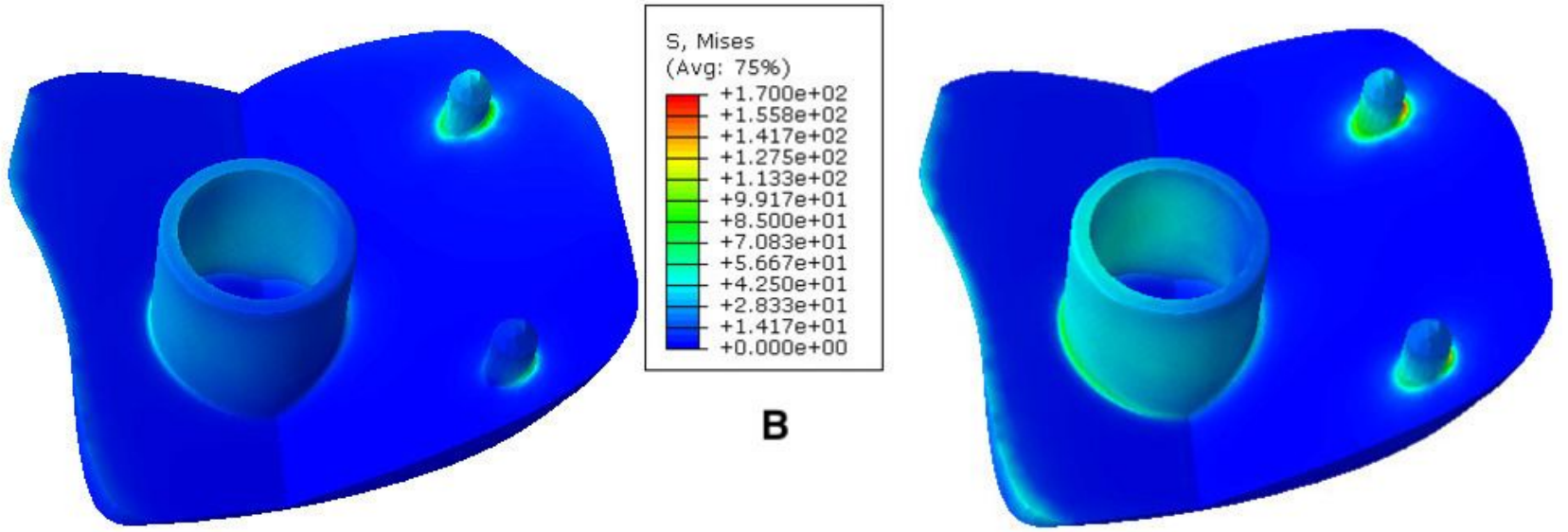

Figure 12

Stress distribution of the Type-1 (A. Load 1; B. Load 2) 


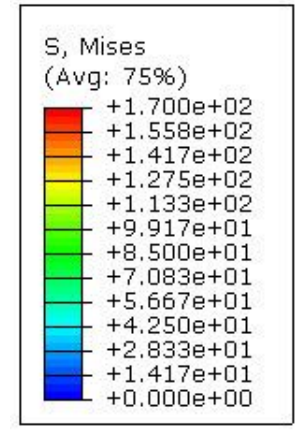

A
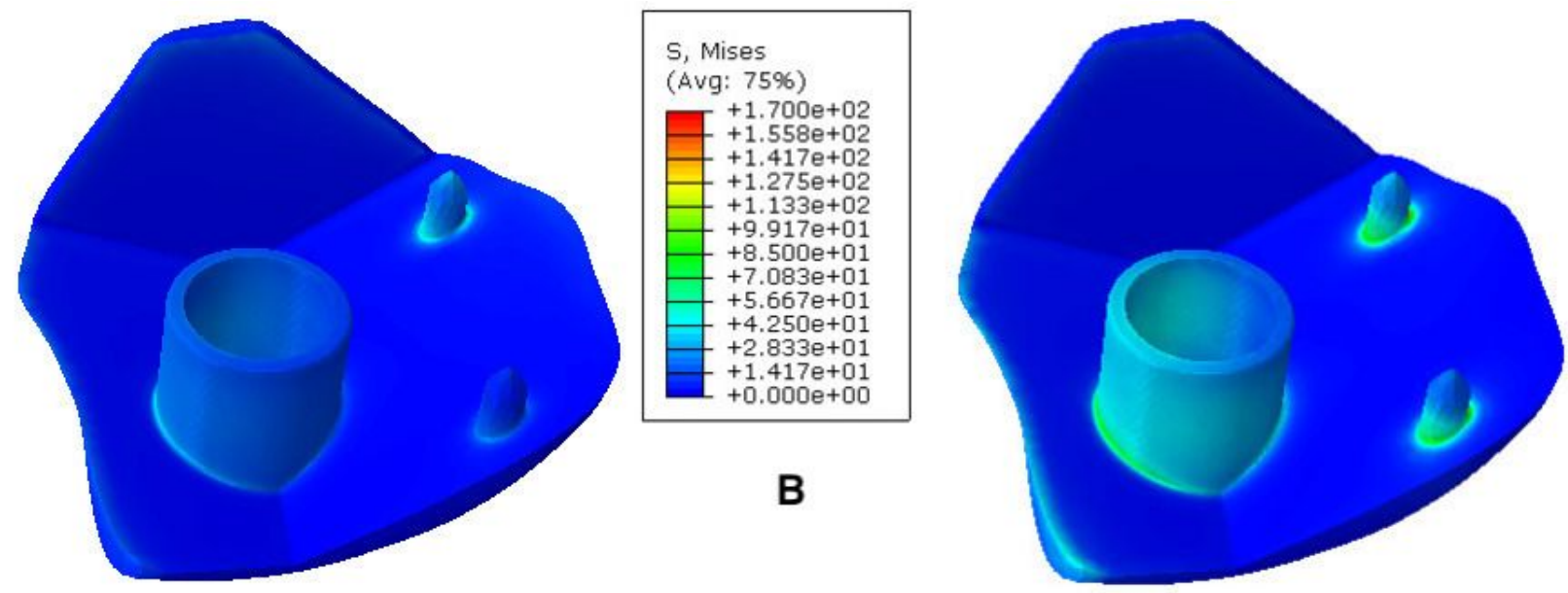

Figure 13

Stress distribution of the Type-2(A. Load 1; B. Load 2

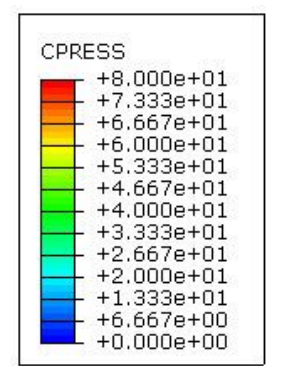

A

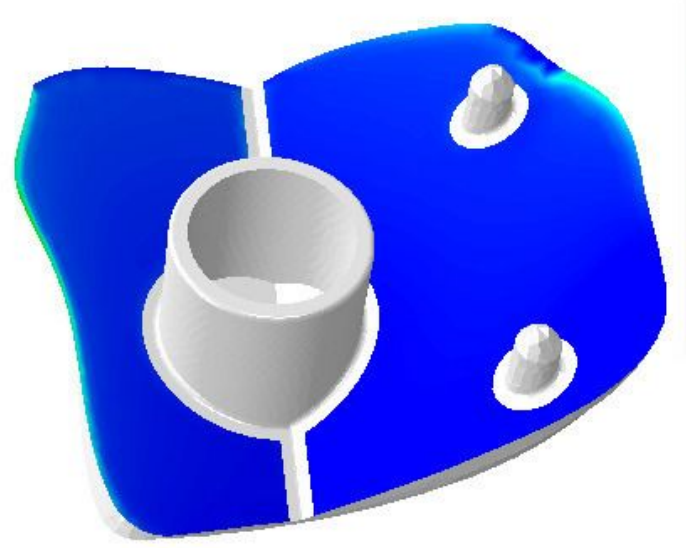

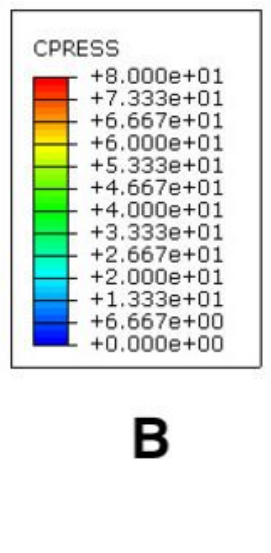

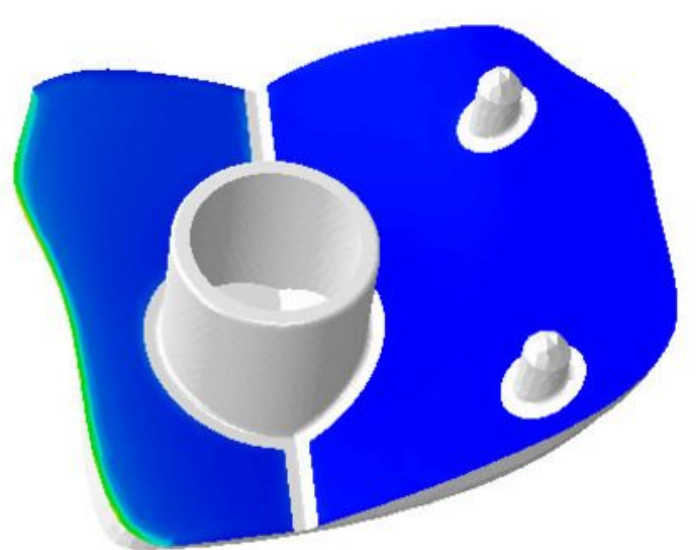

Figure 14

CPRESS distribution on the contact surface of Type-1(A. Load 1; B. Load 2)

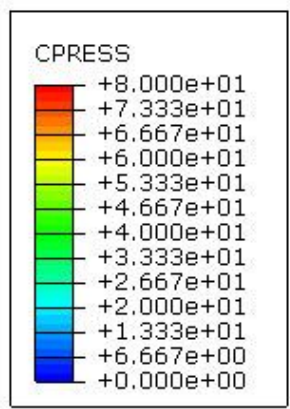

A

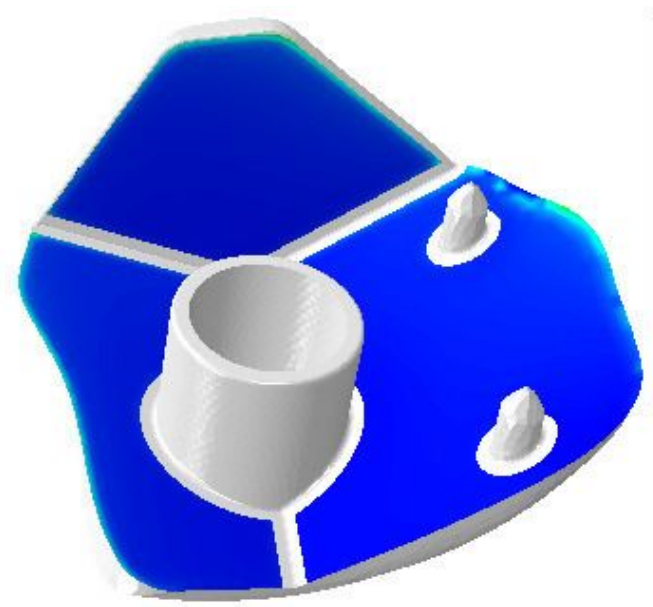

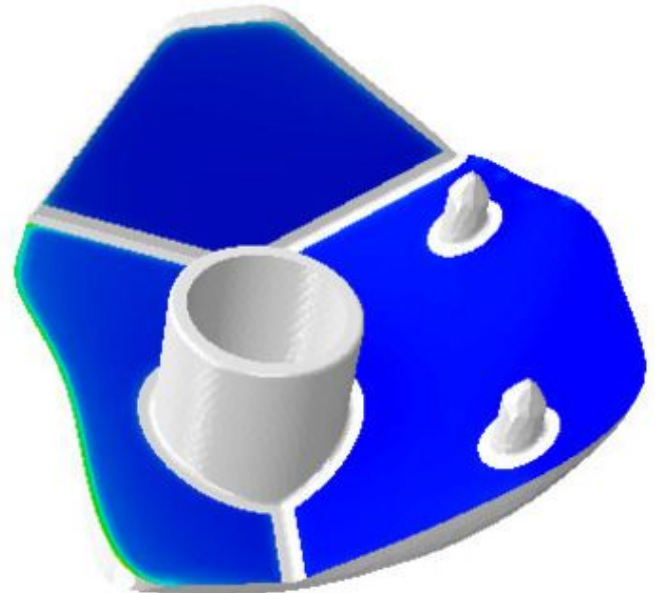

Figure 15

CPRESS distribution on the contact surface of Type-2(A. Load 1; B. Load 2) 

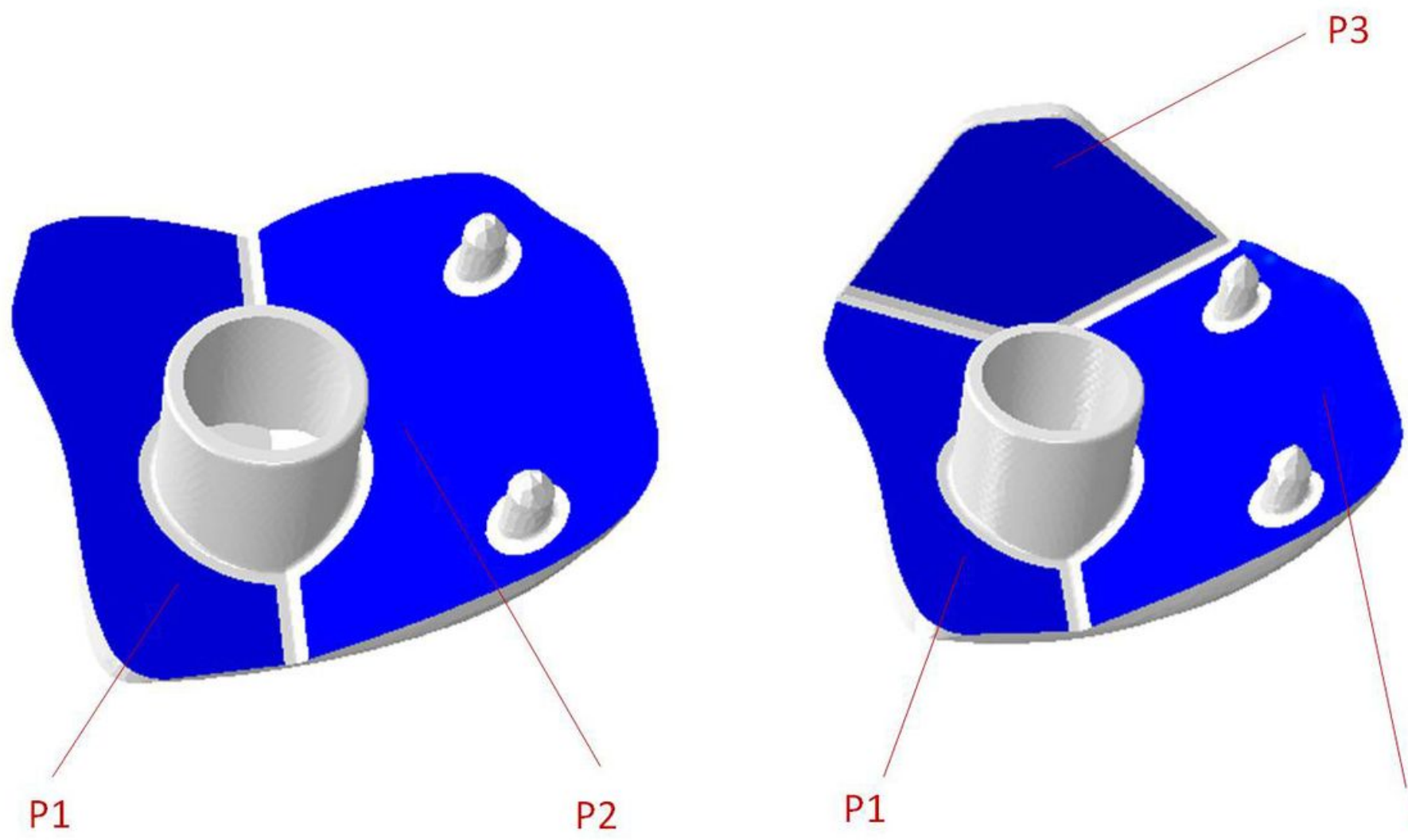

Figure 16

Contact surfaces of the prostheses(P1: Area A; P2: Area B; P3: Area C)
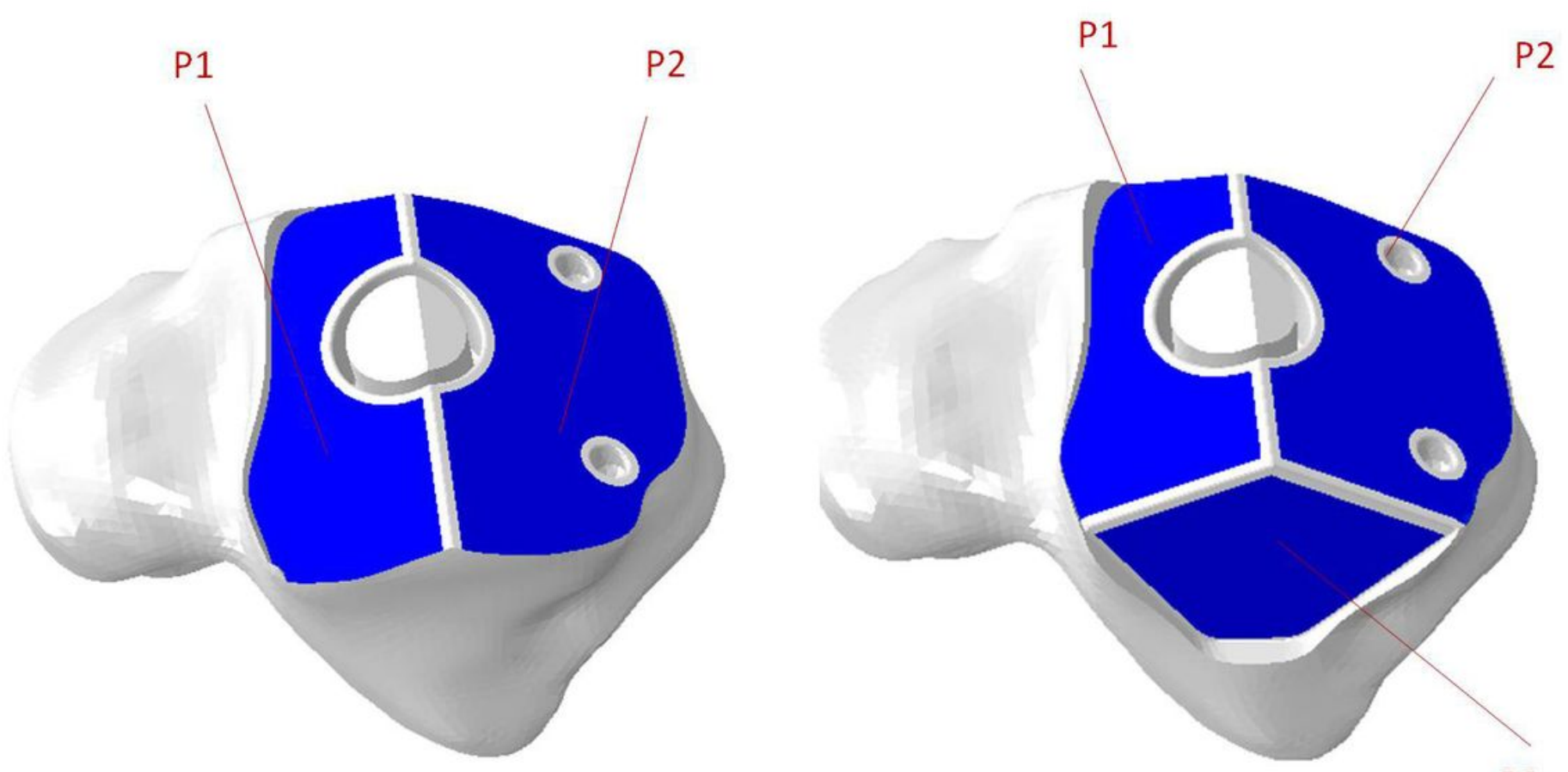

Figure 17

Contact surfaces of talus osteotomy 


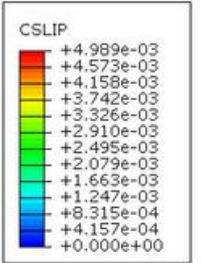

A

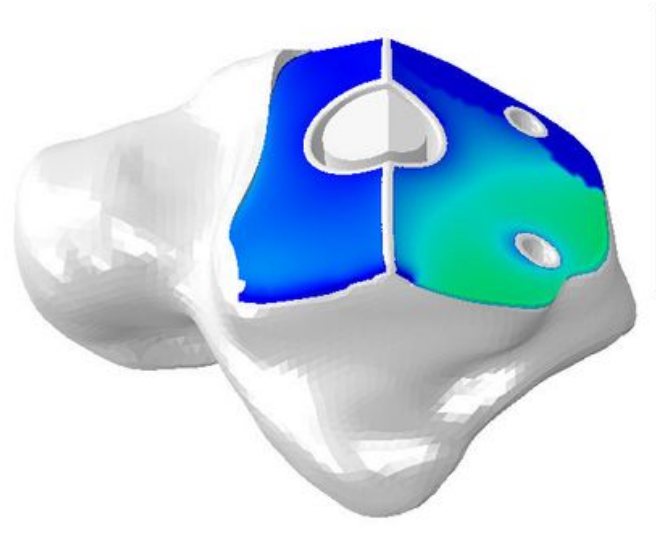

B

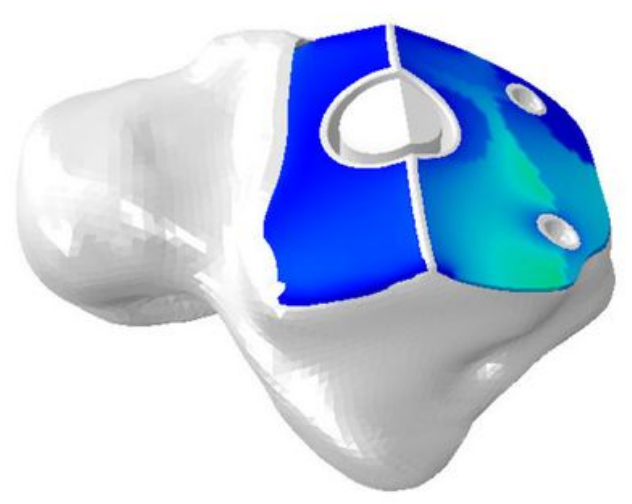

Figure 18

CSLIP of Type-1 under Load (A. Load 1; B. Load2)

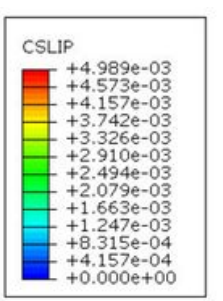

A
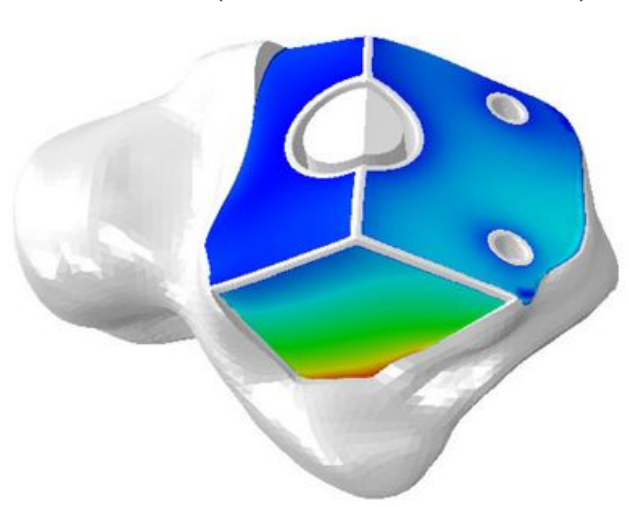

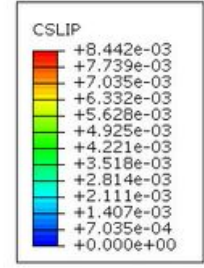

B

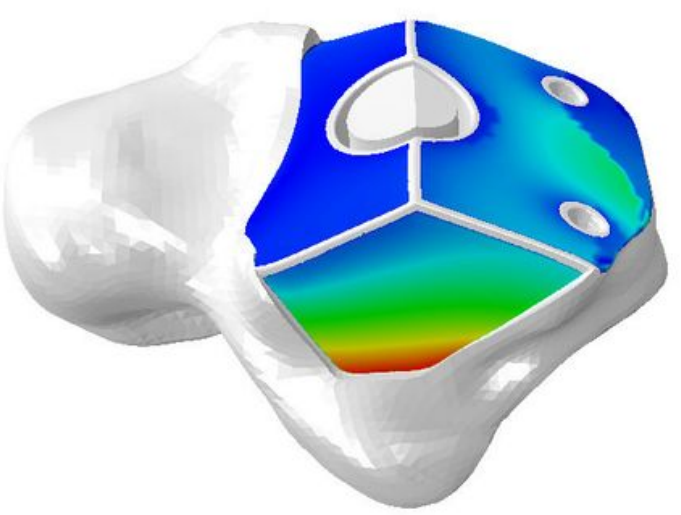

Figure 19

CSLIP of Type-1 under Load (A. Load 1; B. Load2) 